\title{
Revealing the viscosity changes in lipid droplets during ferroptosis by the
} real-time and in situ NIR imaging

\author{
Baoli Dong ${ }^{1}$, Wenhui Song ${ }^{1}$, Yaru Lu ${ }^{1}$, Yaru Sun ${ }^{1}$ and Weiying Lin ${ }^{1,2^{*}}$ \\ 1 Institute of Fluorescent Probes for Biological Imaging, School of Chemistry and Chemical \\ Engineering, School of Materials Science and Engineering, University of Jinan, Jinan, Shandong \\ 250022, People's Republic of China \\ 2 Institute of Optical Materials and Chemical Biology, School of Chemistry and Chemical \\ Engineering, Guangxi University, Nanning, Guangxi, 530004, People's Republic of China
}




\section{Table of contents}

Page

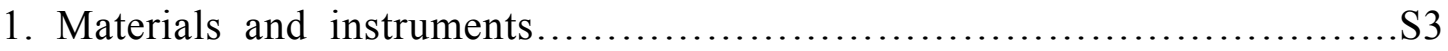

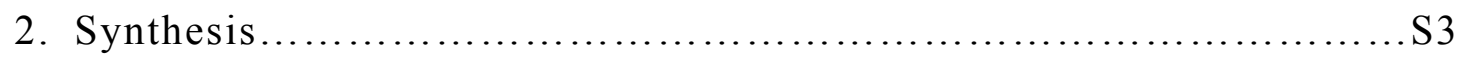

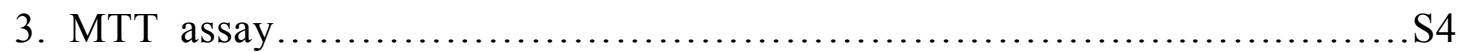

4. Cell culture and fluorescence imaging.............................. 4

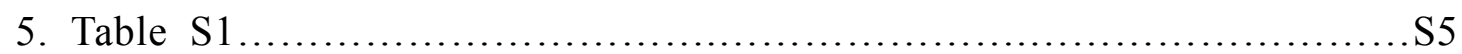

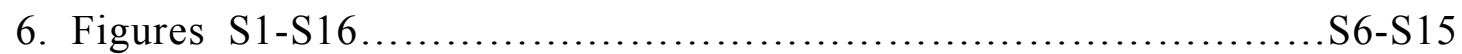

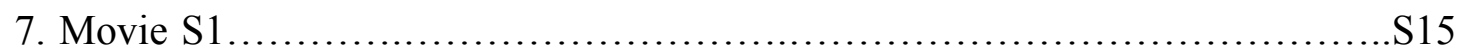




\section{Materials and instruments}

All solvents and reagents were commercially available and used without further purification. Doubly distilled water was used in all the experiments. Thin-layer chromatography (TLC) analysis was performed on silica gel plates and column chromatography was conducted over silica gel (mesh 200-300), both of which were purchased from the Qingdao Ocean Chemicals. Fluorescence spectra and relative fluorescence intensity were measured with a Hitachi F-4600 spectrofluorimeter with a $10 \mathrm{~mm}$ quartz cuvette. UV/vis spectra were obtained with a Shimadzu UV-2700 spectrophotometer. LC-MS were collected using an Agilent 6510 Q-TOF LC/MS. High-resolution mass spectra (HRMS) for the characterization of structures were collected using a Bruker apex-Ultra mass spectrometer (Bruker Daltonics Corp., USA) in electrospray ionization (ESI) mode. ${ }^{1} \mathrm{H}$ and ${ }^{13} \mathrm{C}$ NMR spectra were recorded on an AVANCE III $400 \mathrm{MHz}$ Digital NMR Spectrometer, using tetramethylsilane (TMS) as internal reference. Flow Cytometry Analysis was performed by a flow cytometry (Gallios, Beckman coulter).

\section{Synthesis}

The probe and the control compounds were synthesized as following:

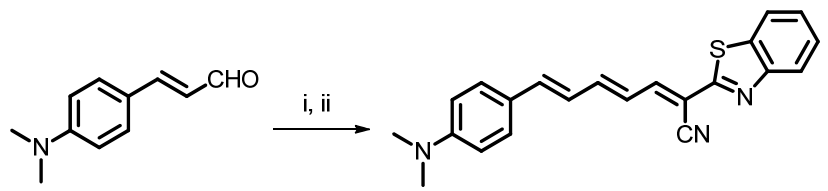

(i) (1,3-Dioxolan-2-ylmethyl)triphenylphosphonium bromide, 18-crown-6, NaH, THF; (ii) benzothiazole-2-acetonitrile, EtOH.

4-(Dimethylamino)cinnamaldehyde $(175 \mathrm{mg}, 1 \mathrm{mmol})$ was dissolved in $10 \mathrm{~mL}$ anhydrous THF, then (1,3-dioxolan-2-ylmethyl)triphenylphosphonium bromide (644 $\mathrm{mg}, 1.5 \mathrm{mmol})$ 18-crown-6 (240 mg, $0.9 \mathrm{mmol})$ and 60\% sodium hydride $(80 \mathrm{mg}, 2$ mmol) were separately added to the reaction mixture, and stirred at room temperature for 30 hours under nitrogen. Thereafter, $10 \mathrm{~mL}$ of $1 \mathrm{mM}$ hydrochloric acid was added and stirring was continued for $30 \mathrm{~min}$. After adjusting the $\mathrm{pH}$ to neutrality with aqueous ammonia, and then extraction was carried out with $60 \mathrm{~mL}$ of 
dichloromethane for three times, and merged organic phase. Next, anhydrous sodium sulfate was added to remove the remaining water until the organic phase was clear. The organic phase was then isolated and purified (petroleum ether-DCM, $\mathrm{v} / \mathrm{v}=1: 1$ ) as an orange solid. Subsequently, the orange solid, benzothiazole-2-acetonitrile $(87 \mathrm{mg}$, $0.5 \mathrm{mmol}$ ) and $50 \mu \mathrm{L}$ DIEA was dissolved and refluxed in $2 \mathrm{ml}$ absolute ethanol for 45 min at $90{ }^{\circ} \mathrm{C}$. Then the solid was precipitated and purified by column chromatography $(\mathrm{PE}: \mathrm{EA}=5: 1)$ to provide atropurpureus compound BDHT $(65 \mathrm{mg}, 37 \%) .{ }^{1} \mathrm{H} \mathrm{NMR}$ (400 MHz, DMSO-d $) \delta 8.13(\mathrm{~m}, 2 \mathrm{H}), 8.03(\mathrm{~m}, 1 \mathrm{H}), 7.56(\mathrm{t}, 2 \mathrm{H}), 7.49(\mathrm{~m}, 2 \mathrm{H}), 7.38$ $(\mathrm{m}, 1 \mathrm{H}), 7.15(\mathrm{~m}, 1 \mathrm{H}), 6.97(\mathrm{~d}, \mathrm{~J}=15.2 \mathrm{~Hz}, 1 \mathrm{H}), 6.82(\mathrm{~m}, 1 \mathrm{H}), 6.79(\mathrm{~m}, 2 \mathrm{H}), 3.02(\mathrm{~s}$, $6 \mathrm{H}) .{ }^{13} \mathrm{C}$ NMR $\left(100 \mathrm{MHz}, \mathrm{CDCl}_{3}\right) \delta 162.7,153.8,147.7,147.5,141.9,134.7,129.1$, 126.7, 125.5, 125.3, 123.1, 121.5, 116.0, 112.2, 104.0, 40.2. HRMS (ESI) m/z calcd. For $\mathrm{C}_{33} \mathrm{H}_{32} \mathrm{~N}_{4} \mathrm{OS} ;[\mathrm{M}+\mathrm{H}]^{+}$533.2370, found 533.2376.

\section{MTT assay}

The cytotoxicity of BDHT was evaluated using the MTT assay. HeLa cells (or 4T1, A549, HepG2 cells) were seeded into 96 well-plates. After 24 h, various concentrations of BDHT were added into wells for the further cultured of $24 \mathrm{~h}$. Then, $10 \mu \mathrm{L}$ of MTT $(5 \mu \mathrm{g} / \mathrm{mL})$ were mixed into cells for incubated another $4 \mathrm{~h}$. After that, $100 \mu \mathrm{L}$ of DMSO were used to resolve the formazan, and then the plate was shaken for $30 \mathrm{~min}$. Finally, the absorbance was determined at $570 \mathrm{~nm}$ by a microplate reader (Thermo Fisher Scientific). Cell viability was expressed as a percentage of the control culture value.

\section{Cell culture and fluorescence imaging}

HeLa cells were cultured in modified Eagle's medium supplemented with $10 \%$ calf bovine serum in an atmosphere of $5 \% \mathrm{CO}_{2}$ and $95 \%$ air at $37{ }^{\circ} \mathrm{C}$. Then cells were seeded into $35 \mathrm{~mm}$ glass-bottom culture dishes and cultured for $24 \mathrm{~h}$.

(1) Colocalization experiments: The HeLa cells were seeded into glass bottom dishes with appropriate density. After $24 \mathrm{~h}$, the cells were treated with $5 \mu \mathrm{M}$ BDHT for 20 min, and then treated with $2 \mu \mathrm{M}$ BODIPY 493/503 for 10 min. Fluorescence images were acquired with a Nikon A1R confocal microscope.

(2) Fluorescence imaging of the changes of LDs viscosity in live HeLa cells induced by monensin or nystatin: (A) HeLa cells treated with $5 \mu \mathrm{M}$ BDHT for $20 \mathrm{~min}$, rinsed for three times with PBS, and then the cells were imaged; (B) HeLa cells pretreated with $5 \mu \mathrm{M}$ BDHT for $20 \mathrm{~min}$, and then treated with $10 \mu \mathrm{M}$ monensin or $10 \mu \mathrm{M}$ nystatin for another $30 \mathrm{~min}$, and finally the cells were imaged. Fluorescence images were acquired with a Nikon A1R confocal microscope. 
(3) Fluorescence imaging of the changes of LDs viscosity during erastin-induced ferroptosis in live cancer cells: (A) HeLa cells (or 4T1, A549, HepG2 cells) pretreated with $5 \mu \mathrm{M}$ BDHT for $20 \mathrm{~min}$, and then treated with $10 \mu \mathrm{M}$ erastin for various time. (B) HeLa cells (or 4T1, A549, HepG2 cells) pretreated with $5 \mu \mathrm{M}$ BDHT for $20 \mathrm{~min}$, and then treated with $10 \mu \mathrm{M}$ erastin and $15 \mu \mathrm{M}$ Fer-1 for various time. Fluorescence images were acquired with a Nikon A1R confocal microscope.

(4) Fluorescence imaging of the changes of LDs viscosity during RSL3-induced ferroptosis in live cancer cells: (A) HeLa cells (or 4T1, A549, HepG2 cells) pretreated with $5 \mu \mathrm{M}$ BDHT for $20 \mathrm{~min}$, and then treated with $10 \mu \mathrm{M}$ RSL3 for various time. Fluorescence images were acquired with a Nikon A1R confocal microscope.

Table S1. Fluorescence quantum yield $(\Phi)$ of BDHT in the methanol/glycerol mixtures with different viscosities $(\eta / c p)$.

\begin{tabular}{|ccc|}
$\begin{array}{c}\text { Methanol/glycerol } \\
(\mathbf{v} / \mathbf{v})\end{array}$ & $\boldsymbol{\eta} / \mathbf{c p}$ & $\begin{array}{c}\text { Fluorescence quantum yield } \\
(\mathbf{\Phi}) / \%\end{array}$ \\
\hline $\mathbf{0 : 1 0}$ & 955 & 10.9 \\
$\mathbf{1 : 9}$ & 793 & 4.0 \\
$\mathbf{2 : 8}$ & 614 & 2.6 \\
$\mathbf{3 : 7}$ & 325 & 1.8 \\
$\mathbf{4 : 6}$ & 149 & 1.5 \\
$\mathbf{5 : 5}$ & 91.4 & 1.2 \\
$\mathbf{6 : 4}$ & 24.9 & 0.86 \\
$\mathbf{7 : 3}$ & 16.3 & 0.71 \\
$\mathbf{8 : 2}$ & 11.5 & 0.56 \\
$\mathbf{9 : 1}$ & 3.47 & 0.31 \\
$\mathbf{1 0 : 0}$ & 1.53 & 0.12 \\
\hline
\end{tabular}




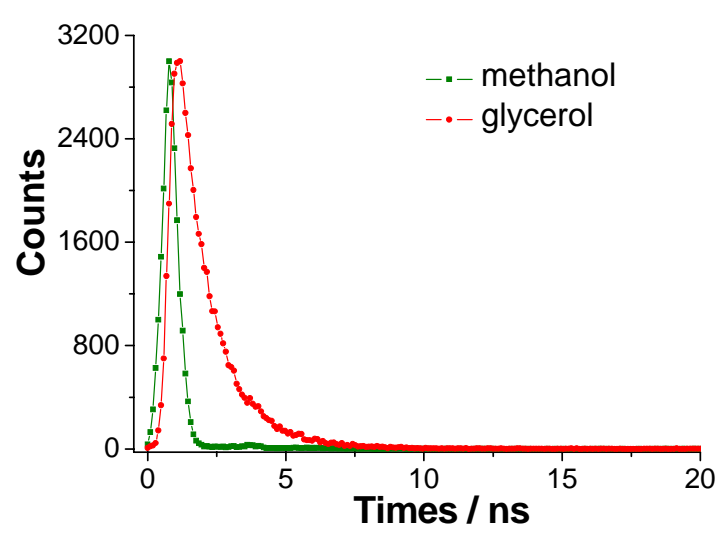

Figure S1 Fluorescence decay of BDHT in methanol and glycerol

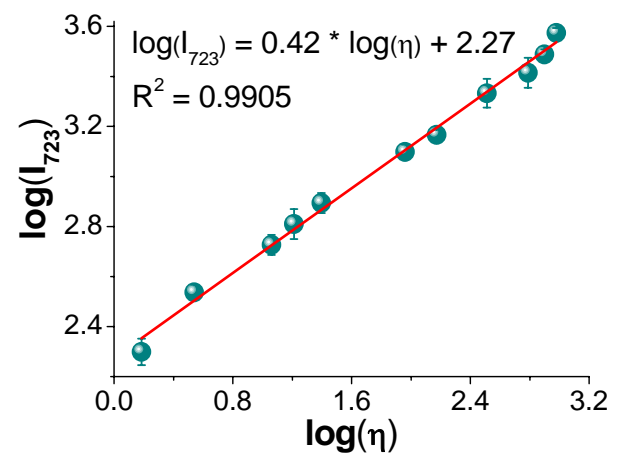

Figure S2 Linear relationship between $\log \mathrm{I}_{723}$ value and $\log \eta$.

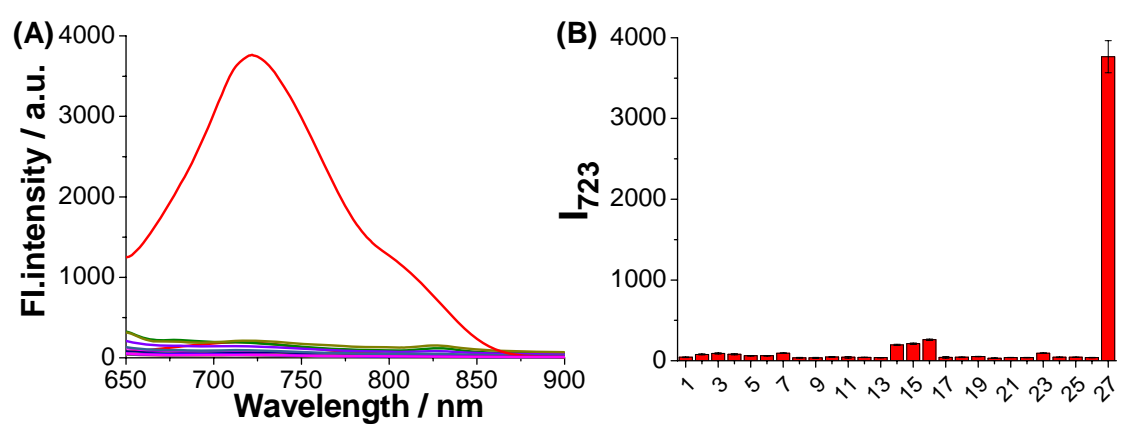

Figure S3 Fluorescence spectra (A) and emission intensity at $723 \mathrm{~nm}$ (B) of $5 \mu \mathrm{M}$ BDHT treated with various species in PBS (pH 7.4, $10 \mathrm{mM}, 5 \%$ DMSO) (1-26) or in pure glycerol (27). 1, Only probe; $2, \mathrm{ZnCl}_{2} ; 3, \mathrm{AlCl}_{3} ; 4, \mathrm{MgCl}_{2} ; 5, \mathrm{CaCl}_{2} ; 6, \mathrm{FeCl}_{2} ; 7$, $\mathrm{Fe}_{2}\left(\mathrm{SO}_{4}\right)_{3} ; 8, \mathrm{CuSO}_{4} ; 9, \mathrm{HgSO}_{4} ; 10, \mathrm{CoCl}_{2} ; 11, \mathrm{Cys} ; 12, \mathrm{Hcy} ; 13, \mathrm{GSH} ; 14, \mathrm{H}_{2} \mathrm{O}_{2} ; 15$, $\mathrm{NaClO} ; 16, \mathrm{OH} ; 17, \mathrm{DTBP} ; 18, \mathrm{NaF} ; 19, \mathrm{NaBr} ; 20, \mathrm{NaF} ; 21, \mathrm{NaNO}_{2} ; 22, \mathrm{NaNO}_{3} ; 23$, $\mathrm{Na}_{2} \mathrm{~S} ; 24, \mathrm{Na}_{2} \mathrm{SO}_{3} ; 25, \mathrm{VC} ; 26$, glucose. Concentration: GSH, $10 \mathrm{mM} ; \mathrm{OH}$ : generated in situ by mixing $50 \mu \mathrm{M} \mathrm{H}_{2} \mathrm{O}_{2}$ into $1 \mathrm{mM} \mathrm{FeSO}_{4}$; other analytes, $100 \mu \mathrm{M}$. $\lambda_{\text {ex }}=620 \mathrm{~nm}$. 


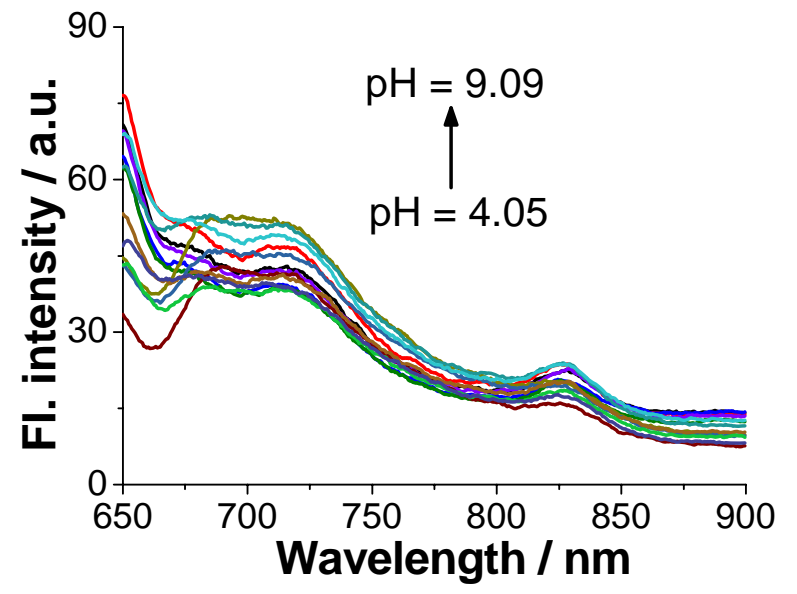

Figure $\mathbf{S 4} \mathrm{pH}-$ dependent fluorescence spectra of $5 \mu \mathrm{M}$ BDHT in PBS (5\% DMSO). $\lambda_{\mathrm{ex}}=620 \mathrm{~nm}$.

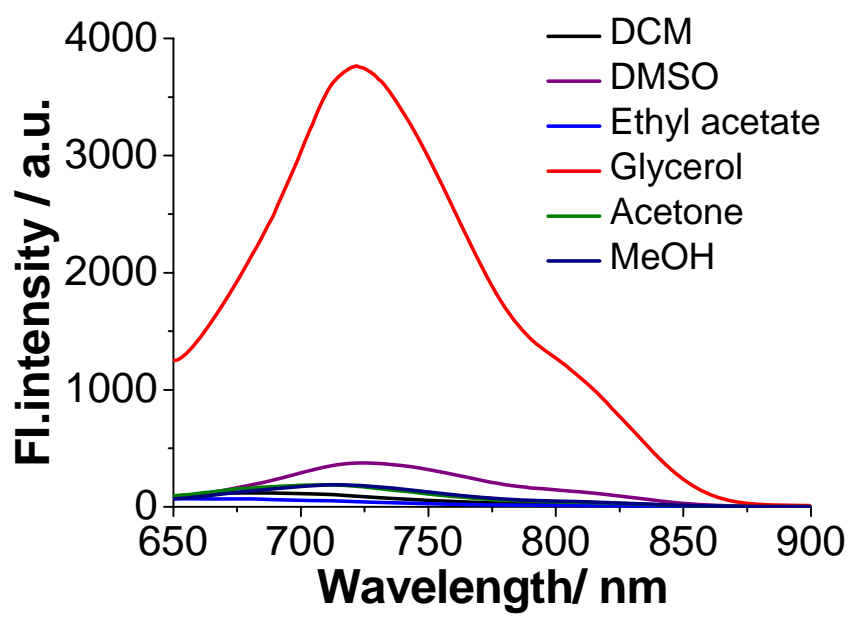

Figure S5 Fluorescence spectra of $5 \mu \mathrm{M}$ BDHT in various solvents. $\lambda_{\mathrm{ex}}=620 \mathrm{~nm}$. 


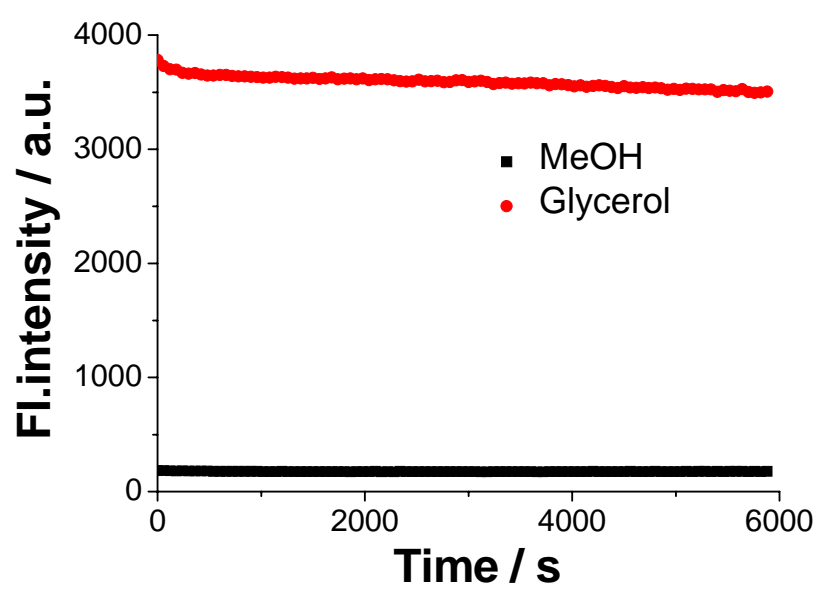

Figure S6 Photo-stability experiments of $5 \mu \mathrm{M}$ BDHT in methanol or glycerol under continuous irradiation by laser light. $\lambda_{\mathrm{ex}}=620 \mathrm{~nm}$.

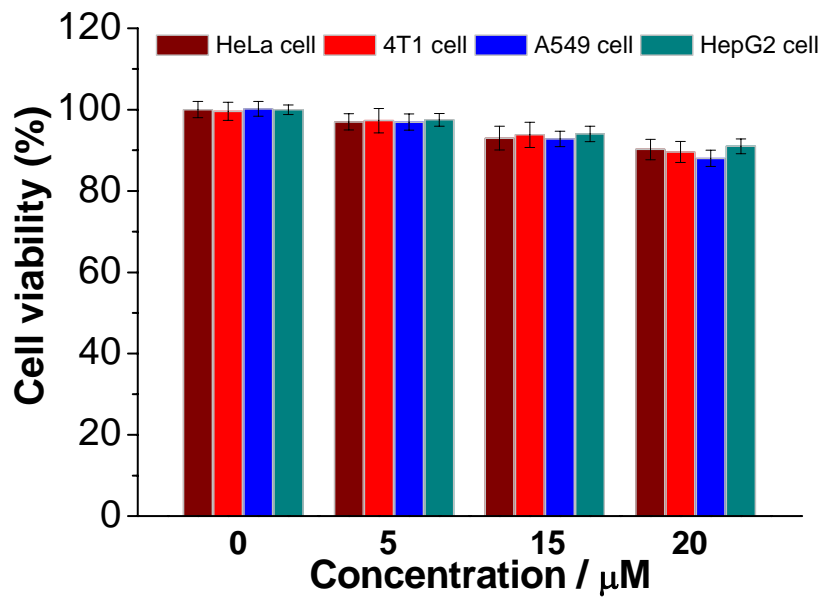

Figure S7 MTT assays of BDHT with different concentrations for various cells. 

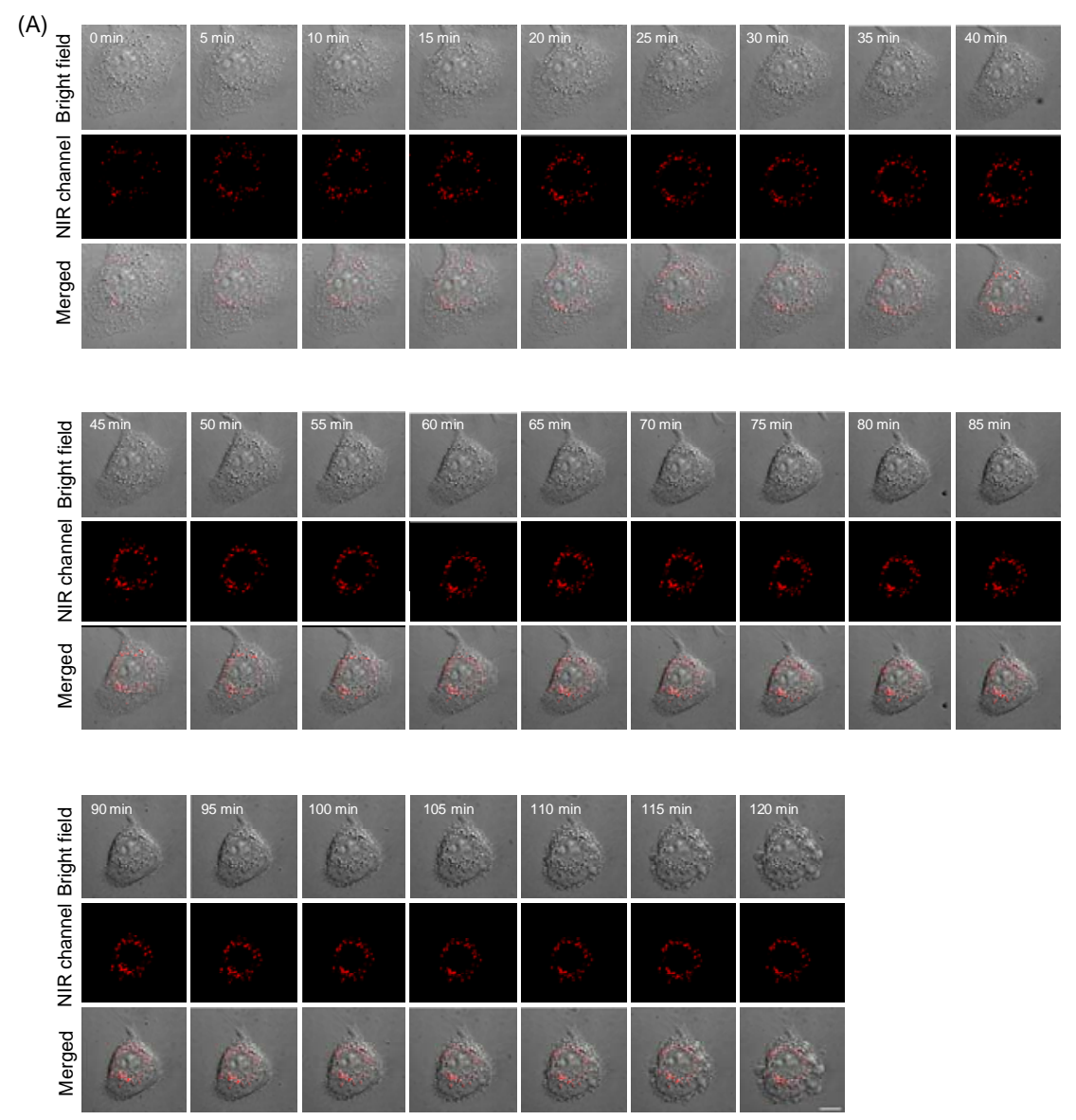

(B)
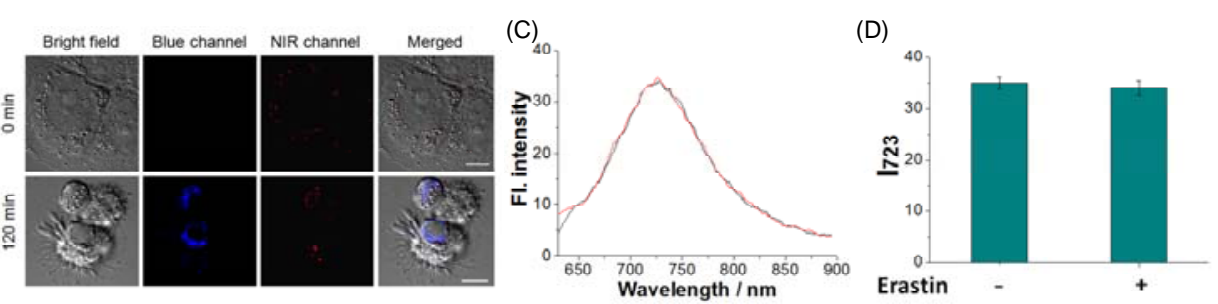

Figure S8 (A) Real-time and in situ fluorescence imaging of HeLa cells pretreated with $5 \mu \mathrm{M}$ BDHT for $20 \mathrm{~min}$ and then treated with $10 \mu \mathrm{M}$ erastin for various time. (B) Fluorescence imaging of HeLa cells pretreated with $5 \mu \mathrm{M}$ BDHT for $20 \mathrm{~min}$ and 10 $\mu \mathrm{M}$ erastin for $0 \mathrm{~min}$ or $120 \mathrm{~min}$, and then incubated with $1 \mu \mathrm{M}$ nucleic acid dye for another $20 \mathrm{~min}$, Scale bar: $10 \mu \mathrm{m}$. Blue channel: $\lambda_{\mathrm{ex}}=405 \mathrm{~nm}, \lambda_{\mathrm{em}}=425-475 \mathrm{~nm}$; NIR channel: $\lambda_{\mathrm{ex}}=561 \mathrm{~nm}, \lambda_{\mathrm{em}}=663-738 \mathrm{~nm}$. Fluorescence spectra $(\mathrm{C})$ and fluorescence intensity at $723 \mathrm{~nm}$ (D) of the cell lysate of the HeLa cells treated with (red) or without (black) $10 \mu \mathrm{M}$ erastin for $2 \mathrm{~h}$ and then stained with $5 \mu \mathrm{M}$ BDHT for $20 \min . \lambda_{\mathrm{ex}}=620 \mathrm{~nm}$. 

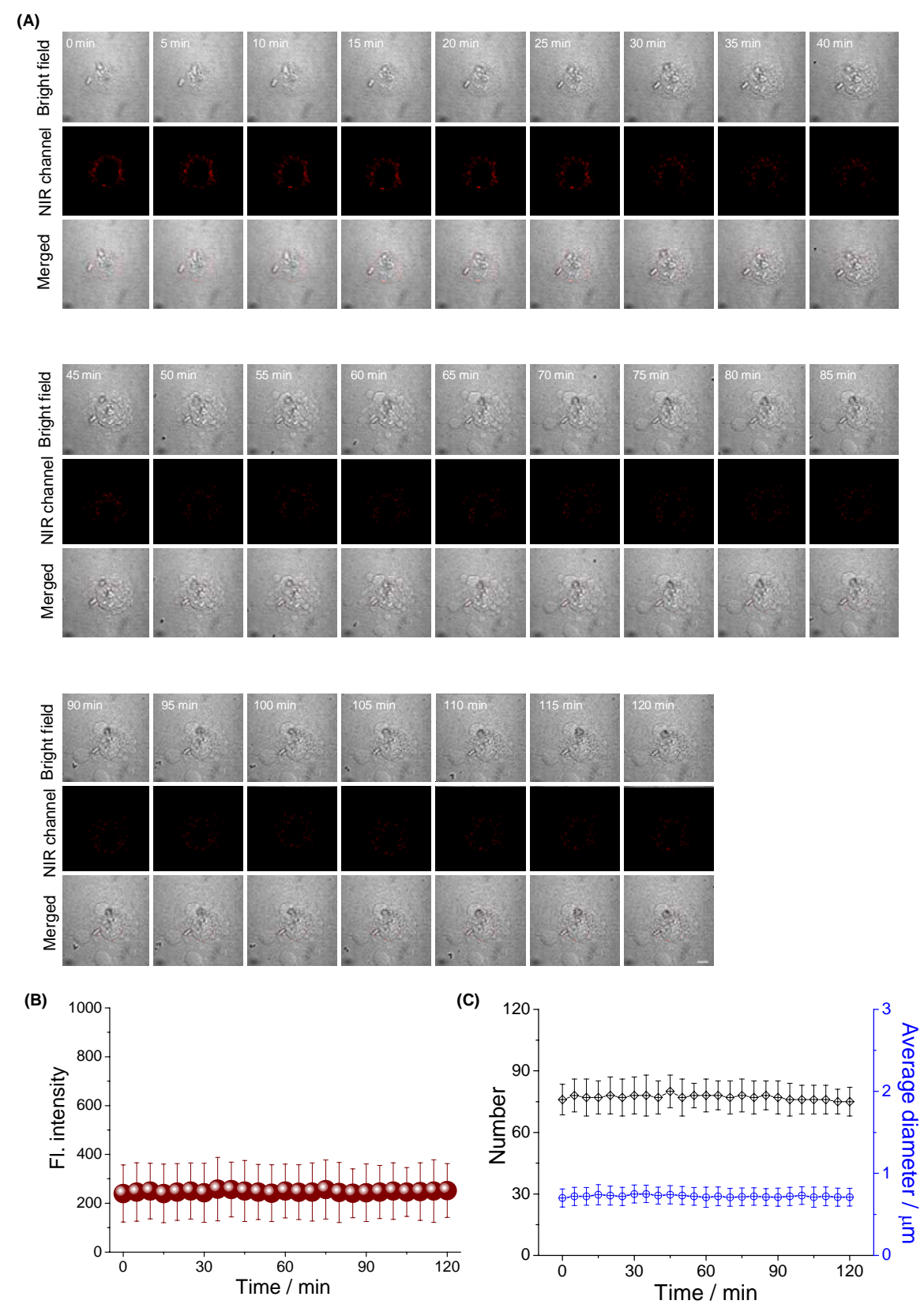

Figure S9 (A) Real-time and in situ fluorescence imaging of HeLa cells pretreated with $5 \mu \mathrm{M}$ BDHT for $20 \mathrm{~min}$ and then treated with $10 \mu \mathrm{M}$ erastin and $15 \mu \mathrm{M}$ Fer-1 for various time. $\lambda_{\mathrm{ex}}=561 \mathrm{~nm}, \lambda_{\mathrm{em}}=663-738 \mathrm{~nm}$. Scale bar: $10 \mu \mathrm{m}$. (B) Relative fluorescence intensity for fluorescence images in (A). (C) Number (black) and average diameter (blue) of LDs at different times. 


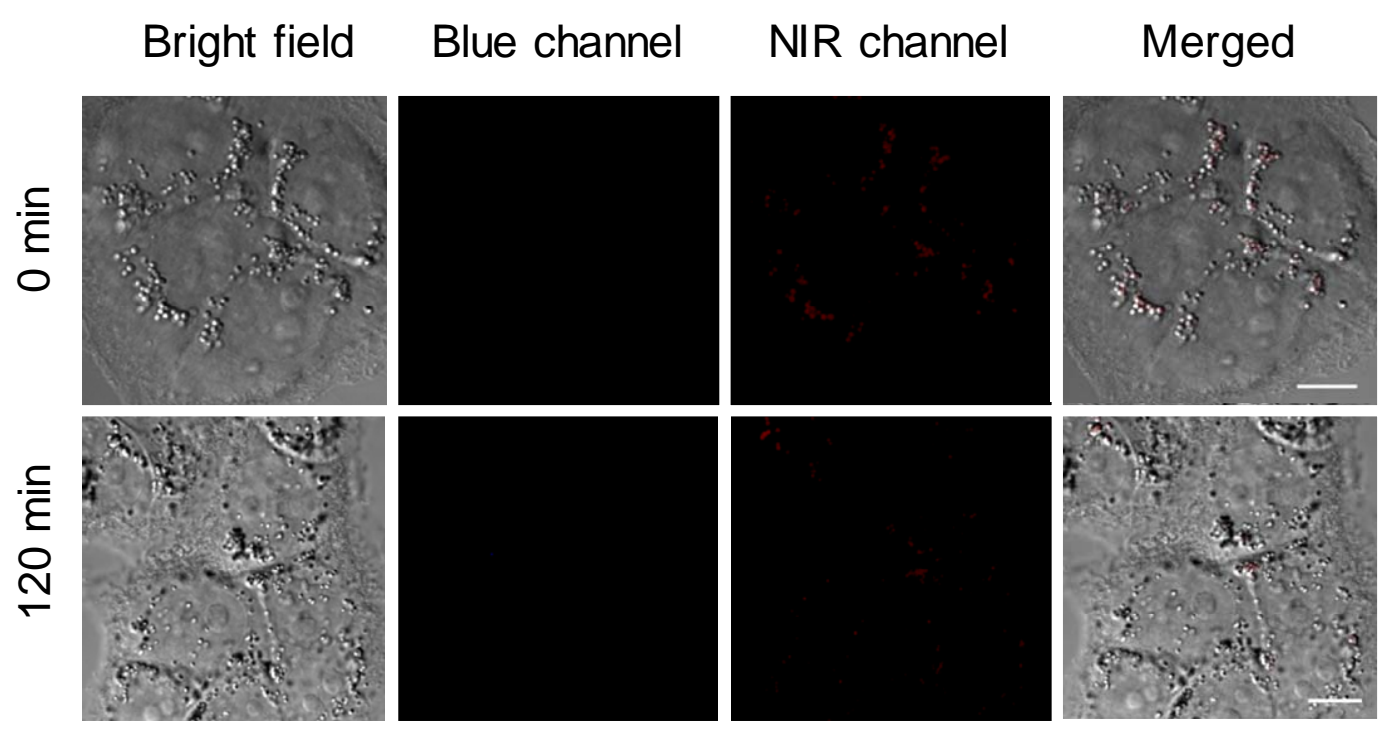

Figure S10 Fluorescence imaging of HeLa cells pretreated with $5 \mu \mathrm{M}$ BDHT for 20 min and $10 \mu \mathrm{M}$ erastin and $15 \mu \mathrm{M}$ Fer- 1 for $0 \mathrm{~min}$ or $120 \mathrm{~min}$, and then incubated with $1 \mu \mathrm{M}$ nucleic acid dye for another $20 \mathrm{~min}$, Scale bar: $10 \mu \mathrm{m}$. Blue channel: $\lambda_{\mathrm{ex}}=$ $405 \mathrm{~nm}, \lambda_{\mathrm{em}}=425-475 \mathrm{~nm}$; NIR channel: $\lambda_{\mathrm{ex}}=561 \mathrm{~nm}, \lambda_{\mathrm{em}}=663-738 \mathrm{~nm}$. 
(A)

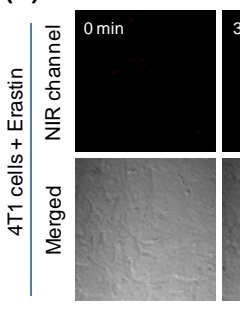

(C)

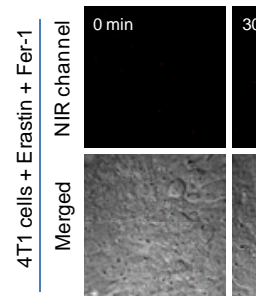

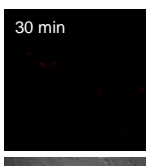
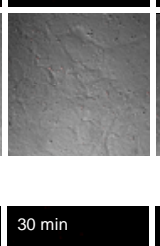

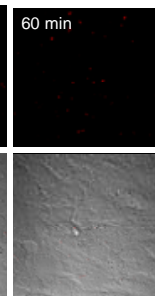

$60 \mathrm{~min}$
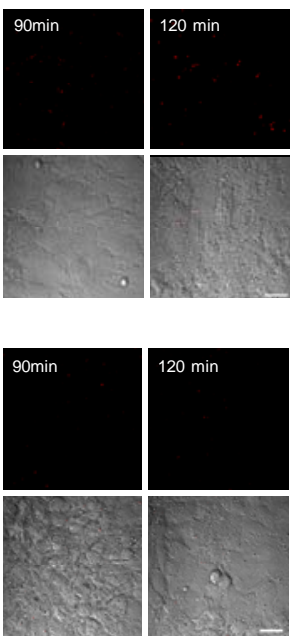

(B)
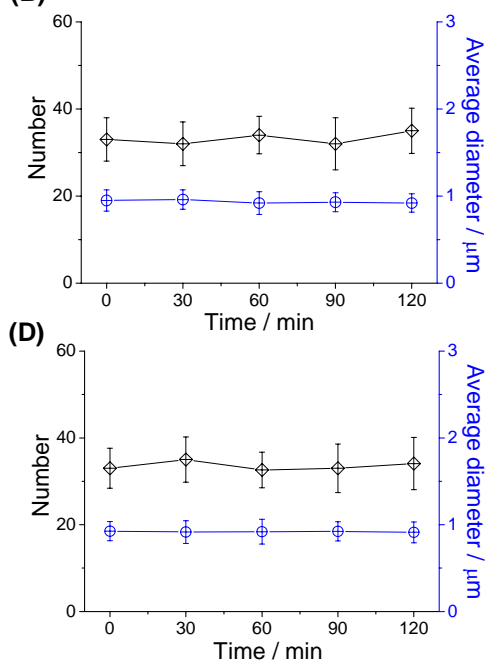

Figure S11 (A) Time-dependent fluorescence imaging of 4T1 cells pretreated with 5 $\mu \mathrm{M}$ BDHT for $20 \mathrm{~min}$ and then treated with $10 \mu \mathrm{M}$ erastin for various time. (B) Number (black) and average diameter (blue) of LDs for (A) at different times. (C) Time-dependent fluorescence imaging of 4T1 cells pretreated with $5 \mu \mathrm{M}$ BDHT for 20 min and then treated with $10 \mu \mathrm{M}$ erastin and $15 \mu \mathrm{M}$ Fer-1 for various time. (D) Number (black) and average diameter (blue) of LDs for (C) at different times. $\lambda_{\text {ex }}=$ $561 \mathrm{~nm}, \lambda_{\mathrm{em}}=663-738 \mathrm{~nm}$. Scale bar: $20 \mu \mathrm{m}$.

(A)

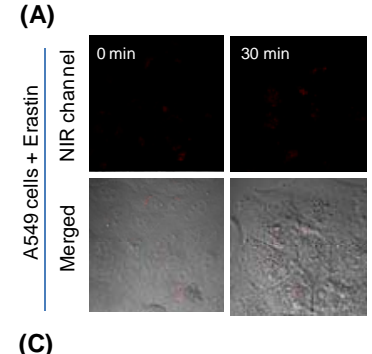

(C)
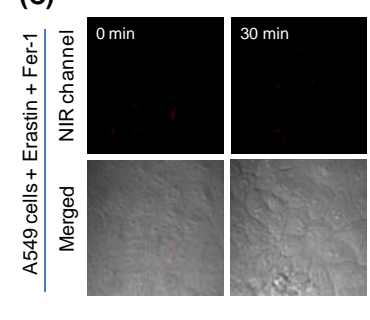

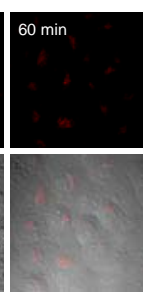

$60 \mathrm{~min}$

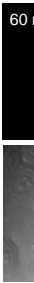

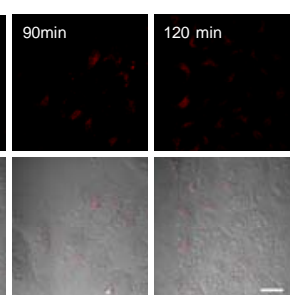

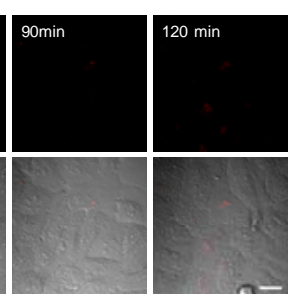

(B)

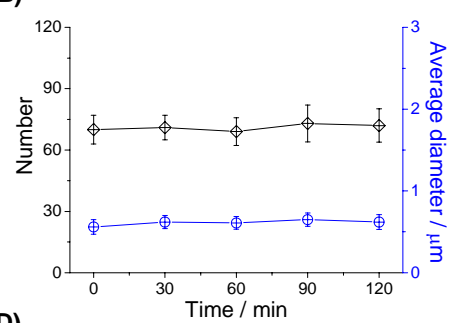

(D)

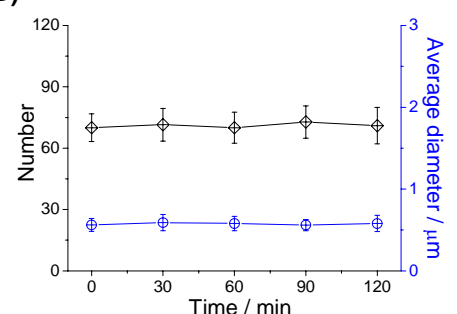

Figure S12 (A) Time-dependent fluorescence imaging of A549 cells pretreated with 5 $\mu \mathrm{M}$ BDHT for $20 \mathrm{~min}$ and then treated with $10 \mu \mathrm{M}$ erastin for various time. (B) Number (black) and average diameter (blue) of LDs for (A) at different times. (C) Time-dependent fluorescence imaging of A549 cells pretreated with $5 \mu \mathrm{M}$ BDHT for 20 min and then treated with $10 \mu \mathrm{M}$ erastin and $15 \mu \mathrm{M}$ Fer-1 for various time. (D) Number (black) and average diameter (blue) of LDs for (C) at different times. $\lambda_{\mathrm{ex}}=$ $561 \mathrm{~nm}, \lambda_{\mathrm{em}}=663-738 \mathrm{~nm}$. Scale bar: $20 \mu \mathrm{m}$. 
(A)

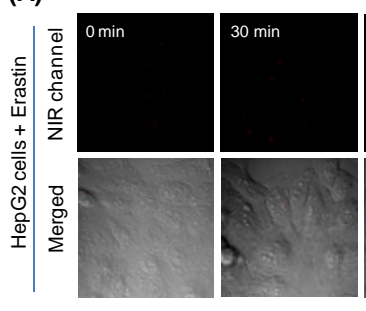

(C)

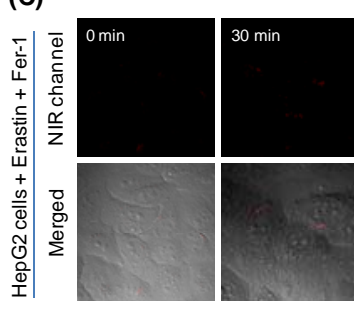

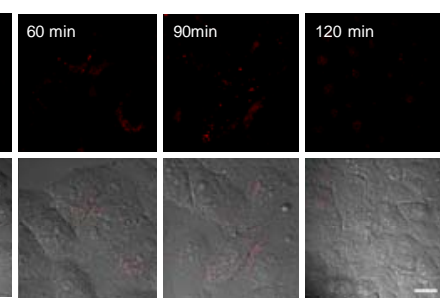

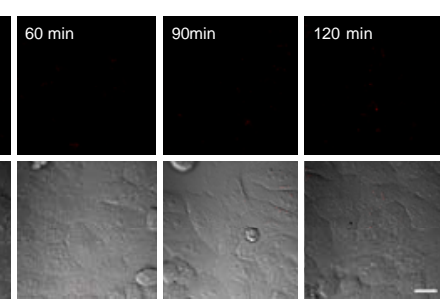

(B)

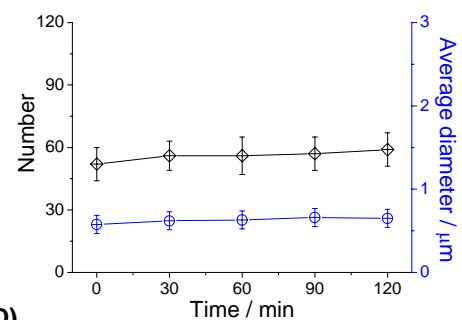

(D)

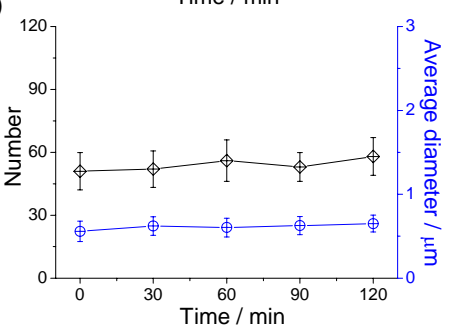

Figure S13 (A) Time-dependent fluorescence imaging of HepG2 cells pretreated with $5 \mu \mathrm{M}$ BDHT for $20 \mathrm{~min}$ and then treated with $10 \mu \mathrm{M}$ erastin for various time. (B) Number (black) and average diameter (blue) of LDs for (A) at different times. (C) Time-dependent fluorescence imaging of HepG2 cells pretreated with $5 \mu \mathrm{M}$ BDHT for $20 \mathrm{~min}$ and then treated with $10 \mu \mathrm{M}$ erastin and $15 \mu \mathrm{M}$ Fer-1 for various time. (D) Number (black) and average diameter (blue) of LDs for (C) at different times. $\lambda_{\text {ex }}=$ $561 \mathrm{~nm}, \lambda_{\text {em }}=663-738 \mathrm{~nm}$. Scale bar: $20 \mu \mathrm{m}$. 

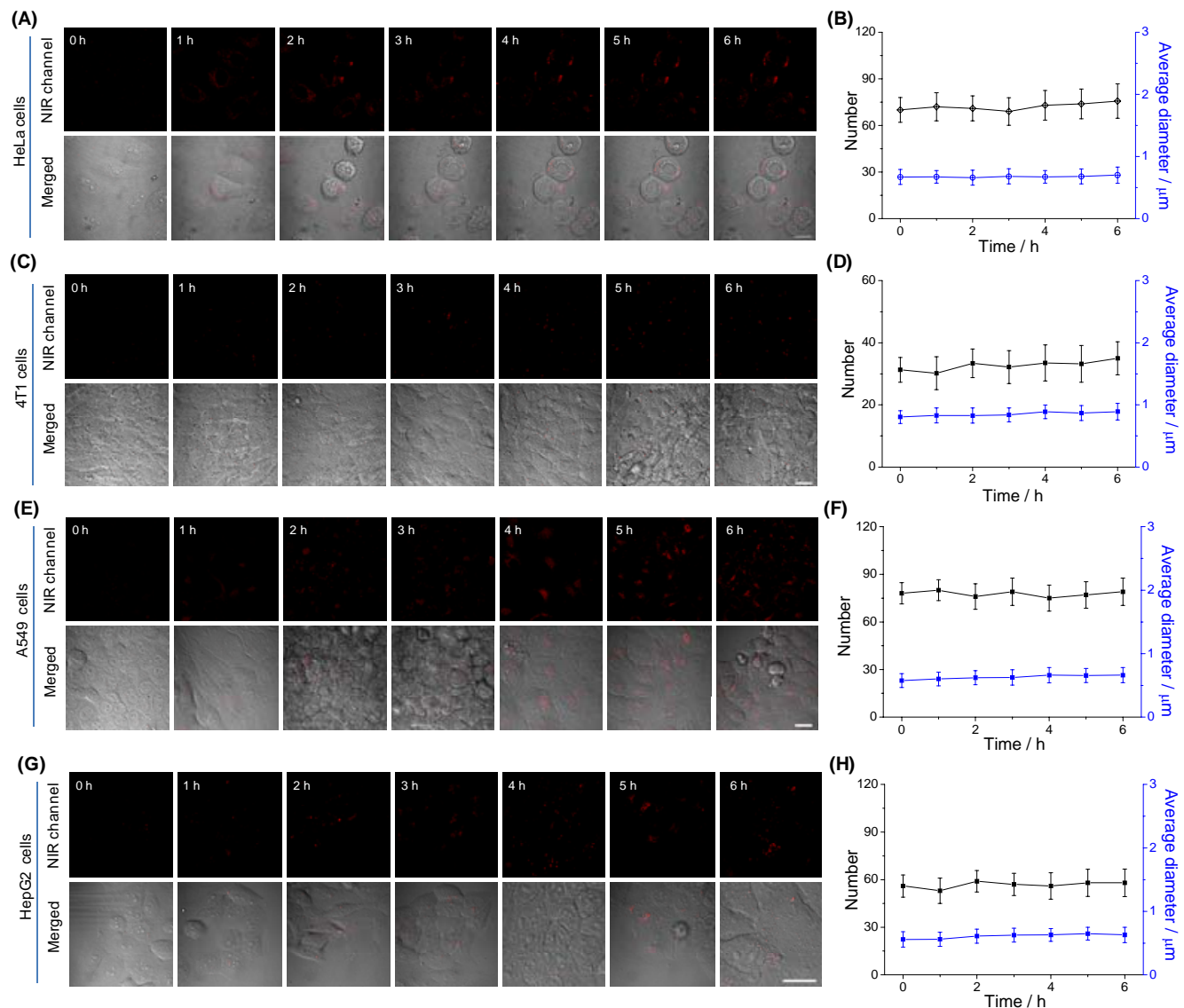

Figure S14 Time-dependent fluorescence imaging of HeLa cells (A), 4T1 cells (C), A549 cells (E), or HepG2 cells (G) pretreated with $5 \mu \mathrm{M}$ BDHT for $20 \mathrm{~min}$ and then treated with $10 \mu \mathrm{M}$ RSL3 for various time. (B), (D), (F) and (H) are the number (black) and average diameter (blue) of LDs at different times for (A), (C), (E) and (G), respectively. $\lambda_{\mathrm{ex}}=561 \mathrm{~nm}, \lambda_{\mathrm{em}}=663-738 \mathrm{~nm}$. Scale bar: $20 \mu \mathrm{m}$. 


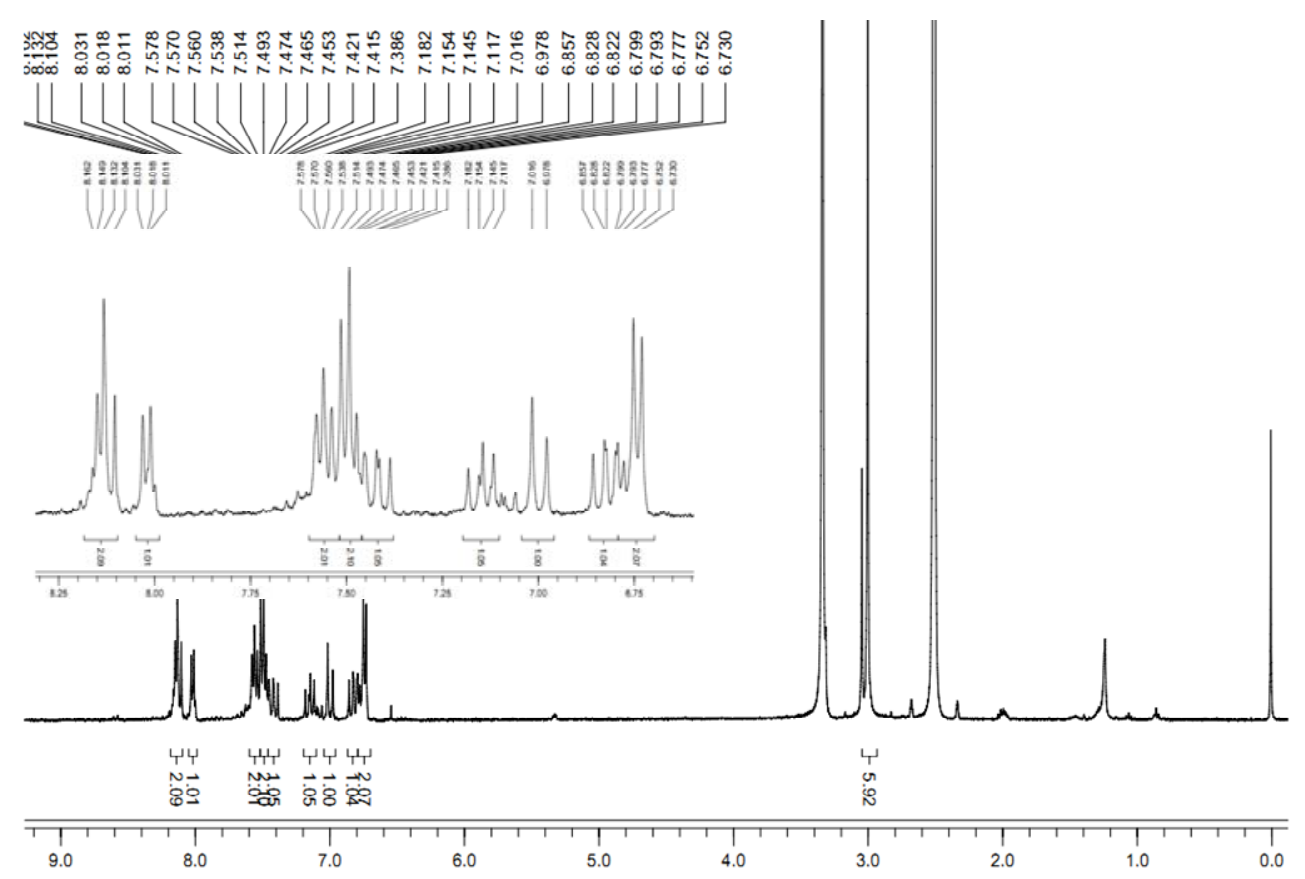

Figure $\mathbf{S 1 5}{ }^{1} \mathrm{H}$ NMR of the probe BDHT (DMSO- $\left.d_{6}\right)$.
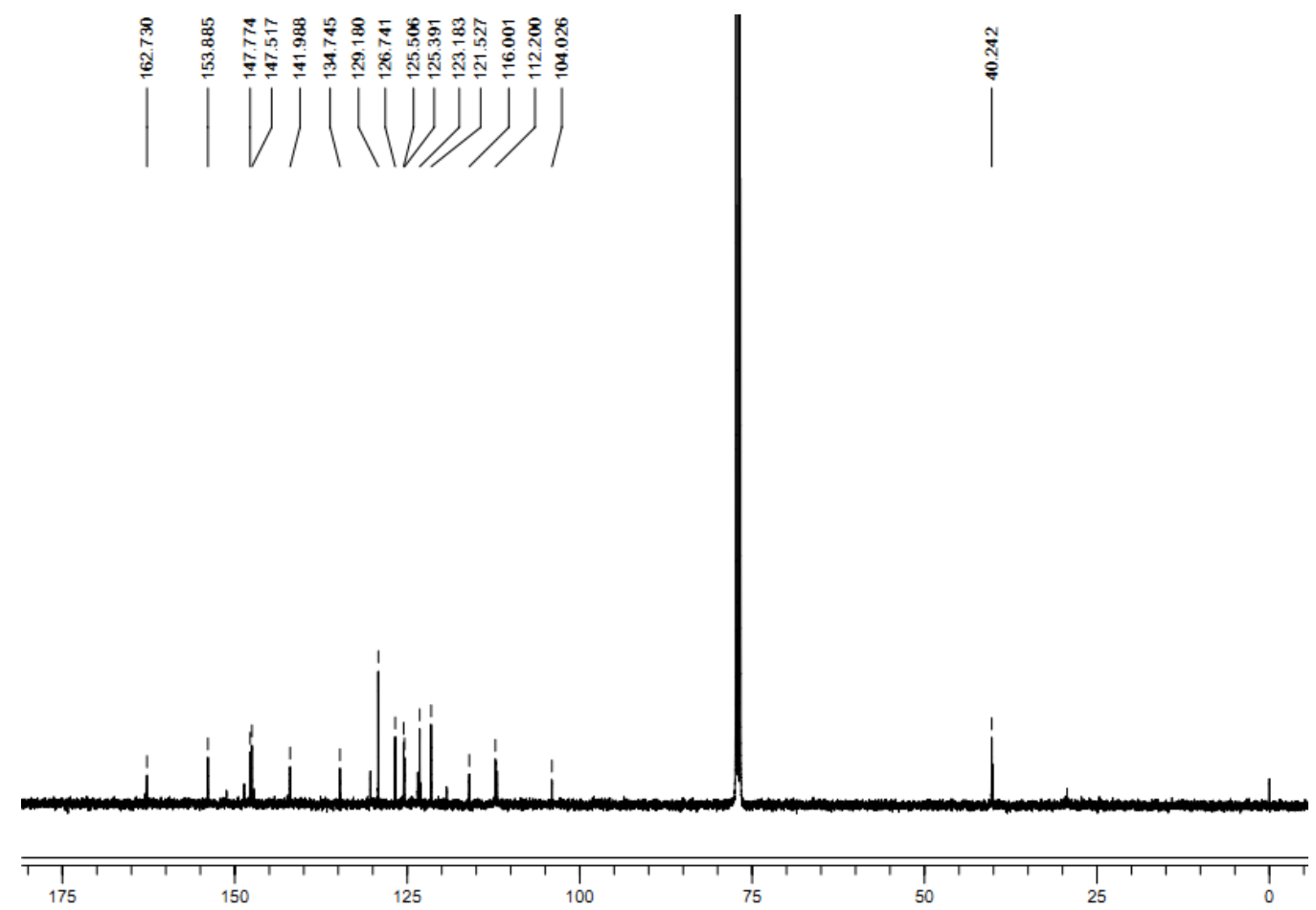

Figure S16 ${ }^{13} \mathrm{C}$ NMR of the probe BDHT $\left(\mathrm{CDCl}_{3}\right)$.

Movie-S1: Real-time and in situ fluorescence images of the HeLa cells pretreated with $5 \mu \mathrm{M}$ BDHT for $20 \mathrm{~min}$ and then treated with $10 \mu \mathrm{M}$ erastin for various time. 